\title{
AN ADAPTED INTERVENTION RESEARCH MODEL: SUGGESTIONS FOR RESEARCH AND PRACTICE
}

\section{H Strydom, MM Steyn, C Strydom}

\section{INTRODUCTION}

The various existing models of intervention research all have advantages and disadvantages. Postgraduate students, and especially doctoral students in Social Work, have on many occasions expressed their dilemma in choosing a specific model of research for intervention procedures. Therefore, many have used the intervention research model or the developmental research and utilisation model, while others have adapted these models to suit their specific research endeavours. After making a careful study of these two models, an adapted intervention research model will be suggested for use in studies of a combined research and practice nature.

\section{OBJECTIVE}

The objective of this article is to evaluate the models of developmental research and utilisation, and intervention research, and to suggest an adapted intervention research (AIR) model to combine and integrate the other models.

\section{PROBLEM STATEMENT}

Bloom, Fischer and Orme (1999) use the term "scientific practitioner", meaning a person using the results of research and evaluation in daily practice, constantly searching for new and more effective ways of serving others, conducting practice as a problem-solving experiment and committing to the values of the helping professions. The focus of social work research has developed from large-scale descriptive studies to applied practice which has qualitative and quantitative elements and can be conducted on a large or small scale (Gibbs, 2001). Fortune and Proctor (2001) call on social work researchers and practitioners to continue research endeavours of an intervening nature. Such studies comprise the essential building blocks for developing practice guidelines with the aim of developing new technology; in the case of the helping professions, this can be called social technology (Thomas, 1981).

Lately more attempts have been made to do research that can be applied in practice, can work towards programmes that can address a specific problem in society, and can be evaluated in order to increase accountability, reliability and validity of interventions. Evaluation has narrowed the social work research tradition to outcome- or ends-based research instead of only exploratory and process-based research (Gibbs, 2001). Powell (2002) argues that research should have relevance for practice. The viewpoints of service users are becoming more important and should form an integral part of intervention studies (Gibbs, 2001).

Social work research is complex and multi-dimensional and should be an area for contested and competing perspectives on a specific topic (Gibbs, 2001). Beytell and Nel (2005) add that the generation of research and theory includes complicated processes and should be followed by researchers, academics, practitioners and students. All participants in such research should become engaged in dialogue as a basis for shared learning, the possibility of reaching some jointly agreed understanding and the achievement of change (Powell, 2002). By critiquing the contributions of others, a lively debate can be set in motion that can only benefit theory and practice. 
FIGURE 1

THE DEVELOPMENTAL RESEARCH AND UTILISATION MODEL

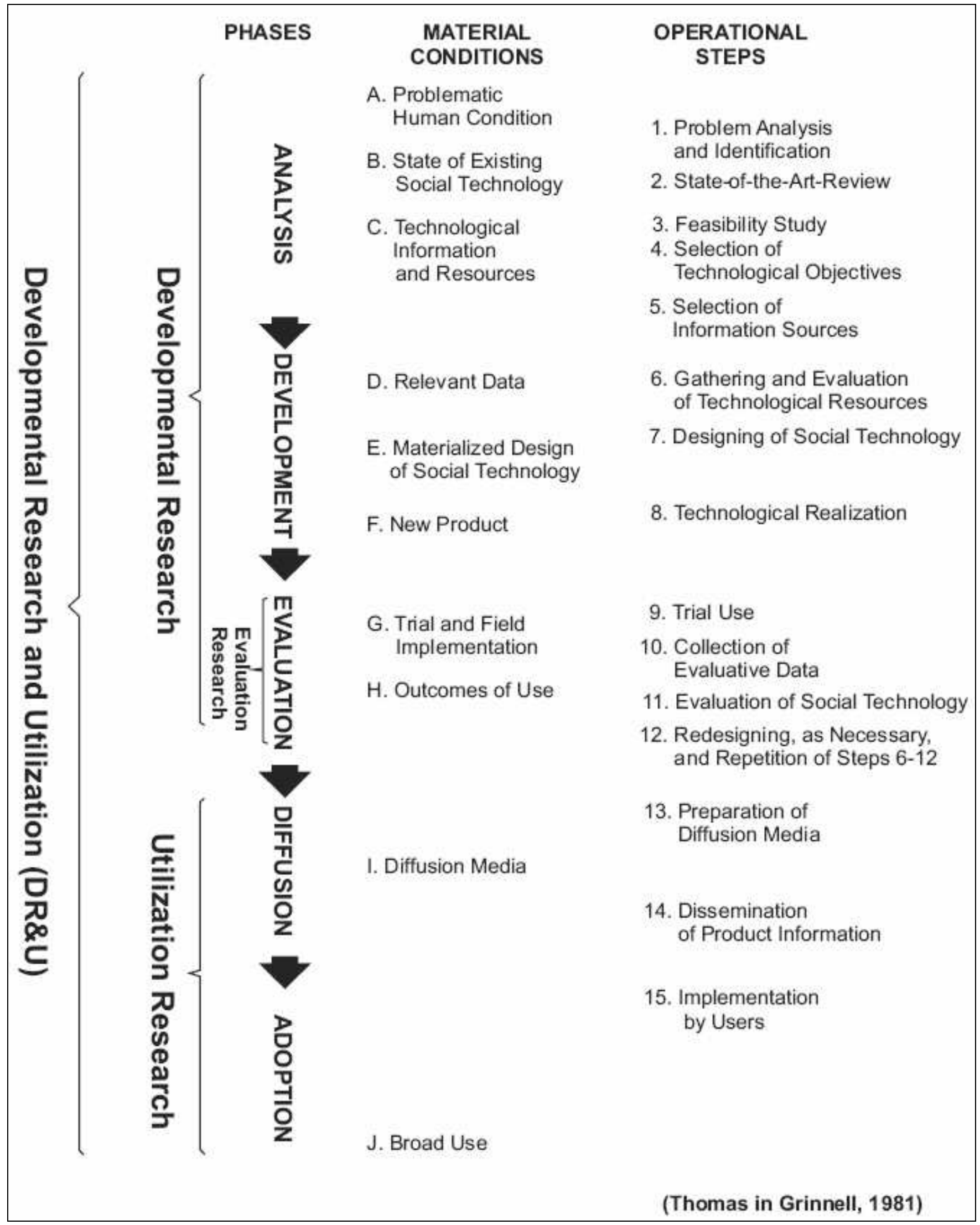




\section{DEVELOPMENTAL RESEARCH AND UTILISATION (DR\&U)}

In the developmental research and utilisation model Thomas (1981) distinguishes developmental research as having three phases, namely analysis, development and evaluation. This delineation of the developmental research model into three phases is also supported by Van Rooyen (1994:279). The evaluation phase can also be seen as evaluation research. The last two phases namely diffusion and adoption are called utilisation research. The full sequence of phases is called the developmental research and utilisation model (DR\&U). In this model certain phases, material conditions and operational steps are delineated (Thomas, 1981). The material conditions are the real, objective phenomena associated with the phases and the consequences of carrying out the steps. The operational steps deal with important components of each phase and involve a set of specific activities to be carried out.

From the literature it seems that the developmental research and utilisation model was developed before the intervention research model. The DR\&U model and specifically the developmental research model, consisting of the first three phases of the DR\&U model, seem to be ideally suited to integrate the theoretical and empirical aspects of social work research (Van Rooyen, 1994:280). The DR\&U model seems to be more practical because of the various ways in which the phases can be used, and although an older model, it is still practised widely. The following examples of doctoral studies that were undertaken using this model can be mentioned. Fouché (1992) was one of the pioneers in South Africa regarding the utilisation of the DR\&U model for her doctoral study. Roux (2002) and Wessels (2003) utilised the DR\&U model for their studies, while Schutte (2004) combined the DR\&U and IR model in her study.

\section{Phase I: Analysis}

During this phase the relevant activities that precede the developmental effort itself receive attention.

\section{Condition A: Problematic human condition}

The first condition is the existence of a social problem towards which the development of social technology can be directed for the purpose of prevention or remediation.

Step 1: Problem analysis and identification

To bring about recognition of the problem, it must be judged as meriting attention.

\section{Condition B: State of existing social technology}

A proper study of existing social technology is necessary in order to ascertain whether or not developmental inquiry is indeed the correct way to go about the project.

Step 2: State-of-the-art review

The assessment of all published and unpublished texts, observation in the field, discussions with knowledgeable persons, conference attendance and workshops should be conducted first-hand.

\section{Condition C: Technological information and resources}

Developmental research derives its data and resources for the development of social technology from various sources, such as basic, applied and indigenous research. These three types of research, when transformed through research utilisation processes, provide contributions to many aspects of social work technology. 
Step 3: Feasibility study

The existing technological information and resources should be applied in the feasibility study, which can be regarded as a fact-finding inquiry to determine whether the attempt is feasible.

Step 4: Selection of technological objectives

The general aim and specific objectives of the study should be clearly delineated and should lead to specific research questions that will give rise to the envisaged new social technology.

Step 5: Selection of information sources

The selection of the most appropriate data sources for the developmental task should subsequently be made.

\section{Phase II: Development}

During this phase, the interventional innovation is created, where the aim and objectives are transformed and moulded into a new product.

Step 6: Gathering and evaluation of technological resources

The selection, evaluation and synthesis of all relevant information for the purpose of technological innovation are important aspects of developmental research that must be considered.

\section{Condition D: Relevant data}

After completion of the evaluation, the result should be a research-produced material condition that consists of relevant data serving as a basis for generating the innovation.

Step 7: Designing the social technology

Designing the social technology should take place now in the sense of moving from research findings to concrete action plans.

\section{Condition E: Materialised design of social technology}

When the design is sufficiently evaluated and becomes precise, it may take its final form.

Step 8: Technological realisation

Actually bringing the product into being takes place in this step, for instance, presenting the programme in pilot form.

\section{Phase III: Evaluation}

This is where the evaluation takes place and it can also be considered to be evaluation research independently.

\section{Condition F: New product}

In the total DR\&U model, evaluation activities form an integral part of a research-innovation process, which begins with the generation of social technology.

Step 9: Trial use

Having produced the product, one needs to evaluate it by way of a pilot implementation.

\section{Condition G: Trial and field implementation}


Step 10: Collection of evaluative data

The pilot implementation, in turn, leads to the collection of evaluative data on a systematic basis for evaluating the innovation.

\section{Condition H: Outcomes of use}

Step 11: Evaluation of social technology

The data that result from the collection of evaluation data provide the basis for embarking on evaluation of the new social technology.

Step 12: Redesigning, as necessary, and repetition of steps 6-12

With this the evaluation phase of this model is completed. If problems arise in the evaluation of the new technology, steps 6-12 can be repeated.

\section{Phase IV: Diffusion}

\section{Condition I: Diffusion media}

After the evaluation phase has been completed and the results prove to be positive, all information on the nature and applicability of the new technology should be prepared and disseminated.

Step 13: Preparation of diffusion media

Activities such as writing articles, books and manuals should take place in this step.

Step 14: Dissemination of product information

The diffusion media are now made available for consideration by potential consumers and peergroup evaluators.

\section{Phase V: Adoption}

Step 15: Implementation by users

The new social technology, in the form of new practice methods or changes in the case of existing programmes, must now be implemented by the users of the product.

\section{Condition J: Broad use}

Broad use of the new social technology can only be achieved if there is widespread diffusion and adoption of the new product.

\section{INTERVENTION RESEARCH (IR)}

Intervention research can be defined as research endeavours with the purpose of conceiving, designing, creating and assessing innovative human interventions applicable to real-world settings in order to solve and prevent problems and maintain quality of life (Comer, Meier \& Galinsky, 2004; De Vos, Strydom, Fouché \& Delport, 2005; Proctor, 2003; Schilling, 1997). Marlow (2005) adds to this definition the modification of the intervention on the recommendations that emerge from the testing. The intervention research model consists of six phases, namely problem analysis and project planning, information gathering and synthesis, design, early development and pilot testing, evaluation and advanced development, and dissemination (De Vos et al., 2005). In each phase a number of material conditions and operational steps can be delineated. Although the model performs in a stepwise sequence, some of the activities continue after the introduction of the next phase, or it can even go back to earlier steps (Rothman \& Thomas, 1994). 
FIGURE 2

THE INTERVENTION RESEARCH MODEL

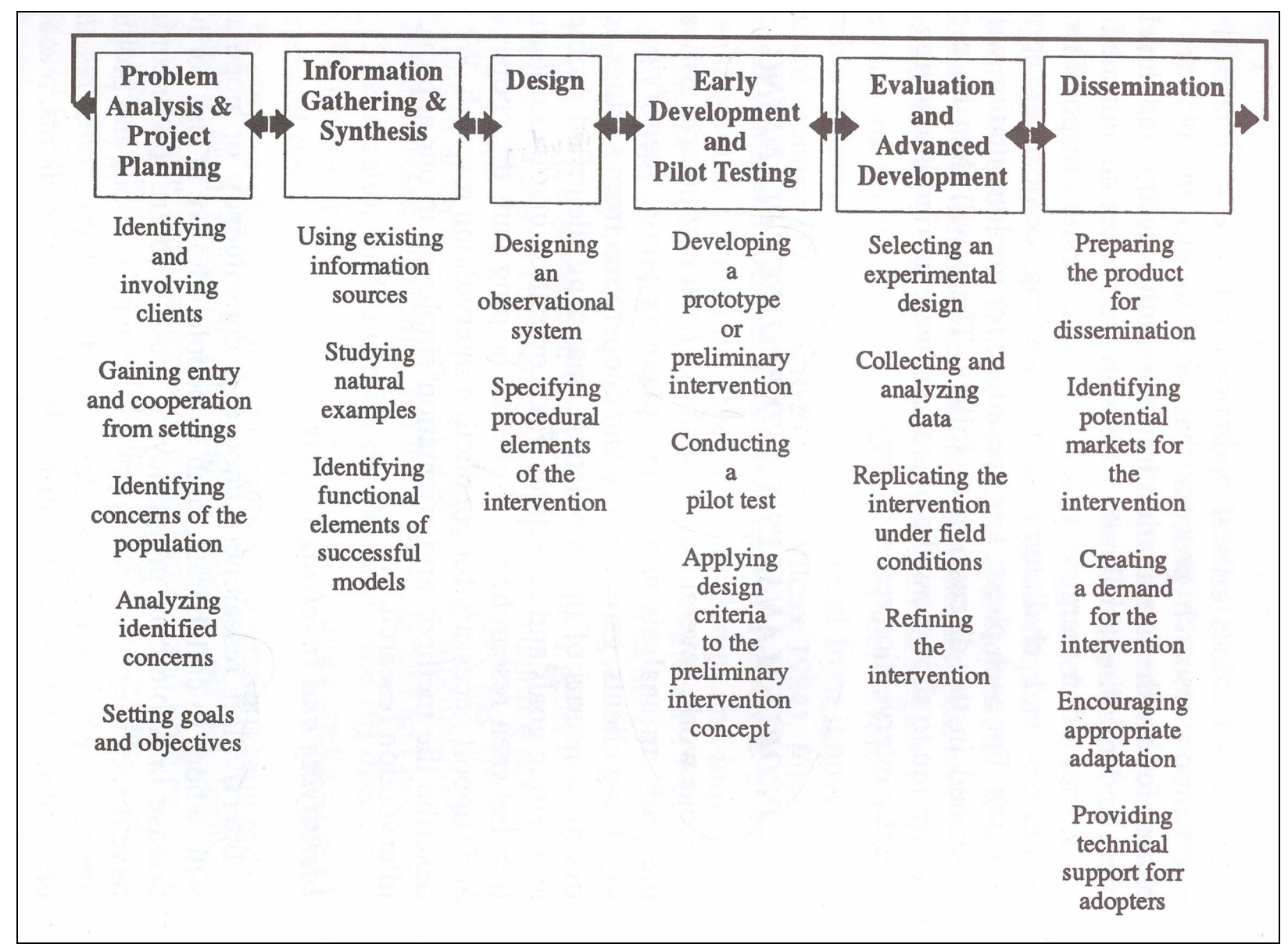

(Rothman \& Thomas, 1994).

Herbst (2002), Strydom (2002) and Van Heerden (2001) can be mentioned as candidates who utilised the entire intervention research model for their doctoral studies. Pretorius (2004) utilised the first three phases of the model in her study, while Steyn (2004) utilised the model without phase four, and Humpel (2004) exchanged phases three and four, in other words she placed early development and pilot testing before the design phase.

\section{Phase I: Problem analysis and project planning}

Social problems in this context can be seen as conditions of society which have negative and undesirable effects on large numbers of people and can be seen as a deviation of some social standard and social disorganisation (De Vos et al., 2005).

Step 1: Identifying and involving clients

A population within a specific social problem is identified on which to do the intended research project.

Step 2: Gaining entry and cooperation from settings

It is important to gain access to a community by way of the correct channels. The details of the project must be explained to the person/s in charge. A collaborative relationship should be formed with all involved so that a sense of ownership can develop. 
Step 3: Identifying concerns of the population

Prospective researchers should endeavour to understand the issues of concern to the population.

Step 4: Analyse concerns

These community problems should be analysed in terms of the negative consequences of the problem for affected people, the discrepancy between the ideal and the actual conditions of the problem, who should be responsible for solving the problem and at what level the problem should be solved.

Step 5: Setting goals and objectives

Stating broad goals and specific objectives clarifies the proposed direction of the project.

\section{Phase II: Information gathering and synthesis}

During this phase, it is essential to discover what has already been done and written on this problem so that the wheel won't be reinvented, and further insight should rather be gained that can follow on from what has already been done.

Step 1: Using existing information sources

A literature review should consist of a study of applicable empirical research, reported practice and identified innovations in the field.

Step 2: Studying natural examples

Research on people who have actually experienced the problem or a similar problem can lead to insight in the way forward. Studying unsuccessful programmes or interventions can lead to a better understanding of the current situation.

Step 3: Identifying functional elements of successful models

Once this information has been gathered, researchers can analyse the potentially useful features of an intervention. This synthesis can help in guiding design and developing activities.

\section{Phase III: Design}

By delineating design into a separate step of the process clear indications are given as to what is to be done during this phase.

Step 1: Designing an observational system

A way of observing events related to the situation and the detection of effects following the intervention is of the utmost importance at this stage of the process.

Step 2: Specifying procedural elements of the intervention

These elements should be specified in sufficient detail in order to be replicated by others, and these elements often become part of an eventual model which can form part of the final product.

\section{Phase IV: Early development and pilot testing}

This is the process through which an innovative intervention is implemented and used on a trial basis.

Step 1: Developing a prototype or preliminary intervention

The preliminary intervention is now developed from all the previous endeavours. 
Step 2: Conduct a pilot study

A pilot study should be implemented in a convenient setting that is similar to the setting where the intervention will take place.

Step 3: Applying design criteria to the preliminary intervention concept

Common guidelines and values for intervention research should already be followed in the preliminary study.

\section{Phase V: Evaluation and advanced development}

The developed programme should now be evaluated and adjustments made accordingly.

Step 1: Selecting an experimental design

There should be room for other designs besides experimental designs. A causal relationship should be established between the intervention and the behaviours and related conditions targeted for change.

Step 2: Collecting and analysing data

This is the stage where data collection and analysis takes place according to the research methodology decided on in the design phase.

Step 3: Replicating the intervention under field conditions

Interventions that are effective in real-life situations with those who actually experience the problem are after all the primary goal of intervention research.

Step 4: Refining the intervention

At this stage adaptations can be made to the content and intervention methods that may produce desired behavioural changes and outcomes of the intervention.

\section{Phase VI: Dissemination}

Once the intervention has been field tested and evaluated, it is ready for dissemination.

Step 1: Preparing the product for dissemination

Aspects such as a name for the programme, the price and standards for the use of the intervention should be established at this stage.

Step 2: Identifying potential markets for the intervention

Potential markets can be defined by way of the establishment of the potential adopters of the programme, such as the beneficiaries, the contributors and the appropriate market segments involved.

Step 3: Creating a demand for the intervention

Potential users of the intervention should be convinced of the benefits for them personally by modelling the innovation, by word of mouth or by advertising.

Step 4: Encouraging appropriate adaptation

Once an innovation has been originally developed, adaptation of it can be made when adopters modify the intervention to suit local conditions. 
Step 5: Providing technical support for adopters

The developers and implementers of the innovation are the primary experts concerning the intervention and should be consulted when adapting the intervention in order to suit specific needs.

\section{THE ADAPTED INTERVENTION RESEARCH MODEL}

From the mentioned examples it is obvious that both models (DR\&U and IR) have been frequently used in studies and that there had even been combinations and integration of the models in some instances. With all of these endeavours, the authors realised that something is lacking in the existing models and that some adaptation of these models might serve a better purpose. Therefore the following adapted intervention research (AIR) model is suggested.

From Figure 3, it can be seen that this model has seven phases with steps in each phase.

\section{Phase I: Delimitation}

This phase consists of the problem identification, the problem formulation, aim/objectives of the study, the pilot study, reporting and making adaptations according to the results of the pilot study.

Step 1: Problem identification

Research normally starts with a vague idea of a social problem in a specific community. At this stage the researcher has no real ideas about the situation and is only vaguely conscious of the possibility of a problem in the particular area of social functioning.

Step 2: Problem formulation

When the vague idea of a possible problem becomes more delineated into a definite problem statement, it can be seen as problem formulation.

Step 3: Aim and objectives

At this stage the broad aim and specific objectives must be delineated in order to give direction to the study.

Step 4: Pilot study

The four aspects of a pilot study should now be carefully considered. They are the preliminary study of literature, the experience of experts, the feasibility of the study and the testing of the measuring instrument.

Step 5: Reporting

The results of the pilot study should now be considered and reported on in order to enhance the necessary changes to the original plan for the study. This report will give directions for the main inquiry and the way forward with the study.

Step 6: Make adaptations

The necessary changes to the plan will subsequently be executed in order to go ahead with the main inquiry. 
FIGURE 3

THE ADAPTED INTERVENTION RESEARCH MODEL (AIR)

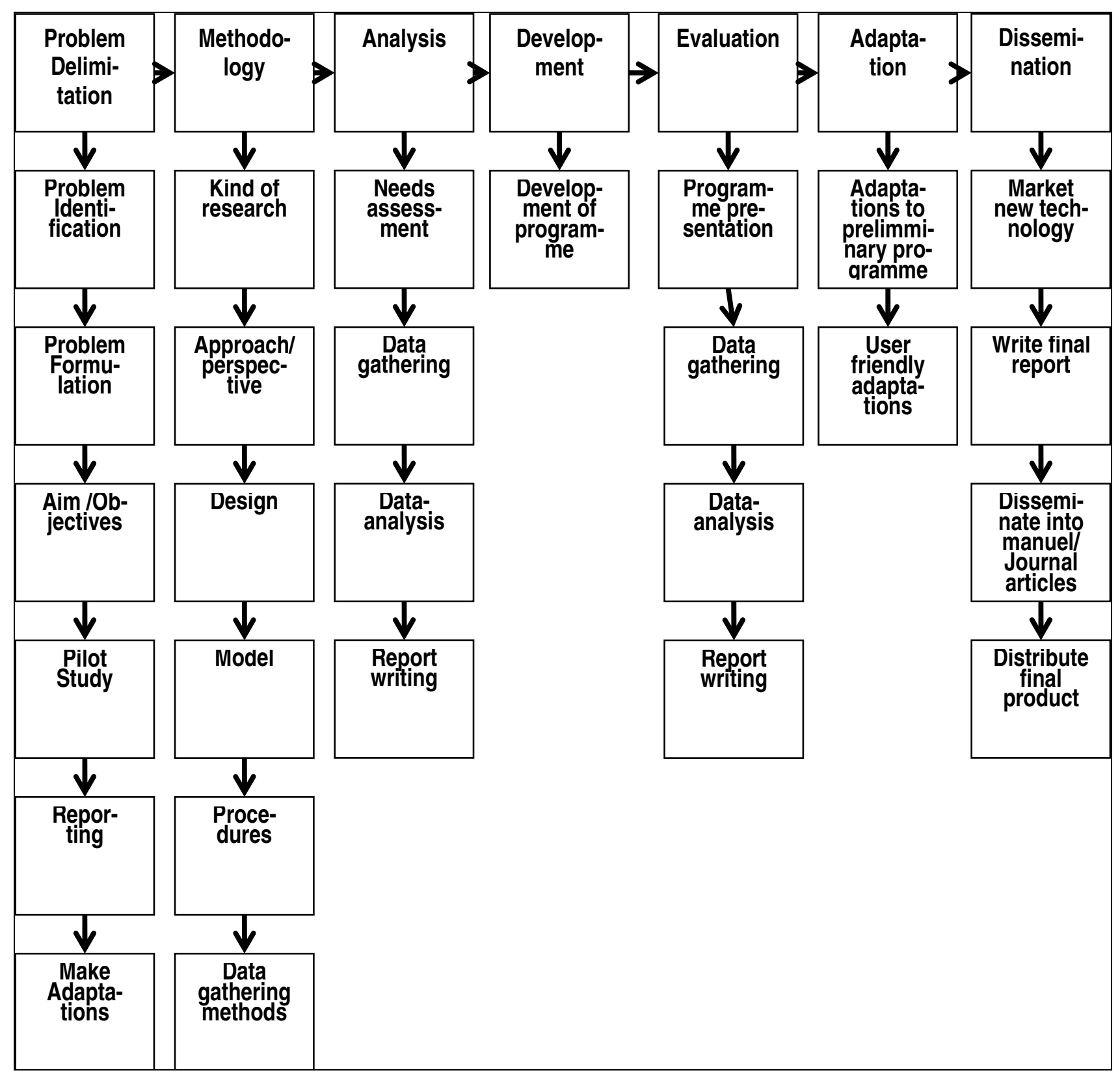

\section{Phase II: Methodology}

During this phase, the methodology for both phases III (analysis) and V (evaluation) must be formulated.

\section{Step 1: Kind of research}

The main emphasis is on the decision whether the project is going to be of a basic or an applied or a combined nature. Most studies done in social work are of a combined nature.

Step 2: Approach/perspective

The decision is whether the study will be of a quantitative or qualitative or combined nature. In most intervention endeavours there is room for a combination of both, in the sense that the analysis phase normally makes use of more quantitative studies, while the evaluation phase is more at a qualitative level. 
Step 3: Design

Basically, the researcher has to decide on either an exploratory, descriptive or explanatory design. In many studies of this nature designs can even be combined. For instance, during the analysis phase the design can be of an exploratory nature, while during the evaluation phase the design can focus on a more explanatory design.

Step 4: Model

In this case, model refers to the adapted intervention research (AIR) model.

\section{Step 5: Procedures}

The procedures for the two phases, namely analysis and evaluation, should be decided on. The procedure can be any one or more of the following, namely single systems, experiment, participant observation, survey research, secondary analysis or case study. The procedure will be chosen in close conjunction with the design.

Step 6: Data-gathering methods

Now the data-gathering method can be embarked on, whether it be self-developed questionnaires, checklists or standardised measuring scales.

\section{Phase III: Analysis}

The data-gathering and analysis of the data from the first phase, normally the more quantitative section of the study, will be conducted during this phase.

Step 1: Needs assessment

A proper needs assessment must be done in order to delineate the problem under investigation. It should be based on proper sampling techniques in order for the data to be representative of all parts of the population.

Step 2: Data gathering

The data will be gathered by way of the appropriate measuring instrument, which can be a selfdeveloped questionnaire to gather more quantitative data.

Step 3: Data analysis

The data will be analysed by statistical means assisted by computer hardware in order to gain information that can help in developing the programme.

Step 4: Report writing

The data should be written up in report form in order to take all the recommendations into consideration when setting up the programme.

\section{Phase IV: Development}

The programme should be developed from the data derived from phase III (analysis) as well as from the literature study on existing programmes.

Step 1: The development of the programme

The programme should now be developed according to the sections of the needs assessment and be properly delineated into various sections that will eventually become the different sessions of the programme. Seeing that the programme is based on the needs of the people, all needs should 
be taken into consideration when compiling the programme. It should be properly conducted according to the aim and content of each session/module and the planning for the next session.

\section{Phase V: Evaluation}

During this phase the data, which is of a more qualitative nature, is gathered and analysed.

\section{Step 1: Programme presentation}

The programme is now presented according to the guidelines developed during phase IV (development). The measuring instrument for a before, middle and after measurement should be ready and used by the researcher. Before and after measurements are the minimum number of measurements in order to ascertain the effect of the programme. However, if more than two measures are done during the course of the programme, it can be said that the measurement is of a more sensitive nature, and the result is even more reliable.

Step 2: Data gathering

The data gathering takes place by way of the specified measuring instrument to gather the more quantitative data from this phase of the project.

Step 3: Data analysis

The various measurements will be compared in order to be able to say that the programme, and hopefully nothing else, caused the changes/growth in the individual, group or community.

Step 4: Report writing

A report should be compiled on the findings of this phase of the project in order to make the final report so much easier.

\section{Phase VI: Adaptation}

No programme can be faultless after it has been newly developed, and adaptations are usually needed on any newly developed social technology. All adaptations should be made in a userfriendly way in order to enhance the marketing of the new social technology.

Step 1: Adaptations to preliminary programme

After the trial run of the newly developed programme, certain adaptations can be made in order to improve the final product.

Step 2: User-friendly adaptation

All adaptations should be made in a user-friendly manner to motivate possible users of the new social technology to make use of it and to spread it to other possible users.

\section{Phase VII: Dissemination}

Disseminating or distributing of the research report is a prerequisite for incorporation of research into practice (Marlow, 2005). The dissemination of a report can be in oral and/or written form and can be published in various manners.

Step 1: Market new technology

The new social technology can be marketed by way of oral and/or written proposals to the population of interested people. 
Step 2: Write final report

The final report should be written from all the field notes and preliminary reports on the various sections of the study that have already been done in previous stages.

Step 3: Disseminate into manuscripts

Journal articles are the best way of disseminating data, because they are more accessible to the specific reading public than, for instance, a report that gets filed in a cabinet or library. The final report on the research done in this manner is usually too long for one journal article and it can often be subdivided into three or four articles, each on a distinct section of the report.

Step 4: Distribute final product

The final report can be distributed in a condensed form of all the individual articles. However, the writer of the report should see to it that the final product follows a logical sequence.

\section{CONCLUSION}

In this article two of the existing models for development and evaluation of interventions were discussed, namely the developmental research and utilisation model (DR\&U) and the intervention research model (IR). Postgraduate students often express the difficulty they experience in deciding on an existing model or on adapting current models to suit their study purpose. After a detailed investigation and discussion of these two models, the authors of this article would like to suggest an adapted intervention research model (AIR) that can perhaps assist in making the task of prospective researchers a bit easier by adding another model that can be utilised in this regard.

\section{REFERENCES}

BEYTELL, A. \& NEL, J.B.S. 2005. Social research and theory generation: An integrated model for research design and method. Die Maatskaplikewerk-Navorser-Praktisyn/The Social Work Practitioner-Researcher, 17(2):215-229.

BLOOM, M., FISCHER, J. \& ORME, J.G. 1999. Evaluating practice: Guidelines for the accountable professional. London: Allyn \& Bacon.

COMER, E., MEIER, A. \& GALINSKY, M.J. 2004. Development of innovative group work practice using the Intervention Research paradigm. Social Work, 49(2):250-260.

DE VOS, A.S., STRYDOM, H., FOUCHÉ, C.B. \& DELPORT, C.S.L. 2005. Research at grassroots: For the social sciences and human service professions. Pretoria: Van Schaiks.

FORTUNE, A.E. \& PROCTOR, E.K. 2001. Research on social work interventions. Social Work Research, 25(2):67-69.

GIBBS, A. 2001. The changing nature and context of social work research. The British Journal of Social Work, 31(5):687-704.

HERBST, A.H. 2002. Life maps as technique in a social group work programme for young adults with HIV/AIDS. Potchefstroom: North-West University. (PhD Thesis)

HUMPEL, H.S. 2004. Pre-aborsieberaad: 'n Maatskaplikewerk-benadering. [Pre-abortion counselling: A social work approach.] Potchefstroom: North-West University. (PhD Thesis)

MARLOW, C.R. 2005. Research methods for generalist social work. London: Thomson Brooks/Cole. 
POWELL, J. 2002. The changing conditions of social work research. The British Journal of Social Work, 32(1):17-33.

PRETORIUS, B.M.L. 2004. Developing a social work practice model for the prevention of relationship violence: A youth perspective. Port Elizabeth: UPE. (DPhil Thesis)

PROCTOR, E.K. 2003. Research to inform the development of social work interventions. Social Work Research, 27(1):3-5.

ROTHMAN, J. \& THOMAS, E.J. 1994. Intervention research: Design and development for human service. New York: The Haworth Press.

ROUX, A.A. 2002. Evaluering van 'n groepwerkhulpverleningsprogramme met MIVpositief/VIGS-pasiënte. [Evaluation of a group work intervention programme for HIVpositive/AIDS patients]. Potchefstroom: North-West University. (PhD Thesis)

SCHILLING, R.F. 1997. Developing intervention research programs in social work. Social Work Research, 21(3):173-180.

SCHUTTE, S.C. 2004. Die ontwikkeling en evaluering van 'n traumabegeleidingsprogram vir slagoffers van plaasaanvalle: 'n Maatskaplikewerk-ondersoek. [The development and evaluation of a trauma guidance programme for victims of farm attacks: A social work study.] Potchefstroom: North-West University. (PhD Thesis)

STEYN, M.M. 2004. 'n Maatskaplikewerkmodel vir ondersteuningdienste aan misdaadgeaffekteerdes in die Noordwes-Provinsie. [A social work model for support services to persons affected by crime in the North-West Province]. Potchefstroom: North-West University. ( $\mathrm{PhD}$ Thesis)

STRYDOM, C. 2002. Evaluation of an HIV/AIDS programme for students at a tertiary institution with emphasis on peer group involvement. Potchefstroom: North-West University. (PhD Thesis)

THOMAS, E.J. 1981. Developmental research: A model for interventional innovation. In: GRINNELL, R.M. (ed) Social work research and evaluation. Itasca: F.E. Peacock Publishers: 590-605.

VAN HEERDEN, L. 2001. Die ontwikkeling en evaluering van 'n lewensvaardigheidsprogram ter verbetering van die maatskaplike funksionering van swart vroeë adolessente. [The development and evaluation of a life skills programme to enhance the social functioning of black early adolescents]. Potchefstroom: North-West University. (PhD Thesis)

VAN ROOYEN, C.A.J. 1994. The developmental research model proposed by Thomas - some thoughts on its use in social work research. Social Work/Maatskaplike Werk, 30(3):276-283.

WESSELS, C.C. 2003. Die opstel en evaluering van 'n maatskaplikewerk-bemagtigingsprogram vir gesinne van MIV-positiewe/VIGS-pasiënte. [The design and evaluation of a social work empowerment programme for families of HIV-positive/AIDS-patients]. Potchefstroom: North-West University. (PhD Thesis)

Prof Herman Strydom, Dr Marie Steyn, Dr Corinne Strydom, School for Psycho-Social Behavioral Sciences: Section Social Work, Potchefstroom Campus of the North-West University, Potchefstroom, South Africa. 